\title{
Gravitational Search Algorithm Based Automatic Load Frequency Control for Multi- Area Interconnected Power System
}

\author{
Samuel Jonas Yeboaha, Solomon Nunoob ${ }^{\mathrm{b}}$, Rajalingam Sakthivelsamy ${ }^{\mathrm{c}}$ \\ ${ }^{a}$ Electrical and Electronic Engineering Department, Sunyani Technical University, P.O Box 206, Sunyani, Ghana. \\ ${ }^{\mathrm{b}}$ Electrical and Electronic Engineering Department, University of Mines and Technology (UMaT), P.O Box 237, Tarkwa, \\ Ghana. \\ ${ }^{\mathrm{c}}$ Electrical and Electronic Engineering Department, Sunyani Technical University, P.O Box 206, Sunyani, Ghana.
}

Article History: Received: 10 November 2020; Revised 12 January 2021 Accepted: 27 January 2021; Published online: 5 April 2021

\begin{abstract}
Demand and frequency deviation is gaining more popularity in power system research especially with multiple power systems interconnections and operations as a result of the complexity of power system network, network upgrade and renewable energy sources integration. However, stability of the power system with respect to momentarily fault of Load Frequency Control (LFC) models, in terms of time taken for the fault to settle, magnitude of overshoot and Steady-State Error (SSE) margin, still remain a challenge to the various proposed LFC designs for power system stability. This paper proposes an intelligent demand and frequency variations controller for a four-area interconnected power system using Gravitational Search Algorithm (GSA) optimisation technique. Proportional Integral Derivative (PID) controller and Gravitational Search Algorithm (GSA) were integrated and implemented on the interconnected power system. The optimised GSA-PID controller demonstrated robustness and superiority with time taken for the instability to settle and maximum overshoot in all the four areas as compared to results with Particle Swarm Optimisation (PSO) PID controller and conventional PID controller under $1 \%$ and $5 \%$ load perturbation. The settling time in all the areas produced tremendous results with GSA-PID controller compared to the results of PSO-PID and conventional PID, the performance of GSA-PID controller shows better dynamic responses with superior damping, less overshoot, minimum oscillations and shorter transient duration.
\end{abstract}

Keywords: Load Frequency Control, Four area power system, GSA technique, GSA-PID controller

\section{Introduction}

Stable power system operation is the main mandate of power system security and protection engineers which is one of the most significant problems researched by many electrical engineering researchers. The modern configuration of a power system is a sophisticated network and highly dynamic with constant exhibition of system instability due to inadequate system damping [1]. Electric Power systems constantly experience changes during unusual operating conditions due to differences in generation or load and also a wide variety of disturbances. Power system stability enhancements have been considered an important issue for secure system operation over several years [2]. Frequency varitations resulting in electromechanical oscillations are distinctive of a power system which are unavoidable. These oscillations are common in most of the power system variables similar to synchronous generator power, line current, bus voltage, and also speed. In general, generator rotor angle control approaches of power system which in effect causes oscillations are divided into two main groups: controlling damping at generator locations such as excitation control and transmission line reactive power injection and absorption control mechanism.

Current version of the power system networks is made up of several power producing units that are interconnected by the help of tie-lines. With such power system, there is a restricted permissible variations with regard to frequency and tie-line flows irrespective of the variations at any section of the interconnection. This is achievable by influencing the operation of speed governor mechanism of steam and hydro turbines with appropriate control strategy [3]. Hence, to enhance stability of a complex network such as four-area interrelated power system, a robust and intelligent LFC is required. In this paper, an optimised Gravitational Search Algorithm (GSA) Proportional-Integral-Derivative (PID) controller for a four-area interconnected power system control of load and frequency deviations in the presence of disturbances is proposed.

The rest of the paper is organized as follows: Section 2 surveys related works on LFC design methods, Section 3 focuses on the design of the GSA-based PID controller. Section 4 describes the proposed technique with adequate mathematical models and its implementations on the power system being investigated. The simulation results of the implemented system are presented and discussed in Section 5 and Section 6 concludes the paper 


\section{Load Frequency Control Design Methods}

When several generating utilities are interconnected, demand and frequency cotrol requirement of each area are supplied by the generating units in that region or else the generating units of another regions interconnected to that region with tie-lines. However, it is important to note that the capability of tie-lines is confined and should not be overloaded. The frequency is considered as a tool for power balance. In case, the generation is lesser than demand, frequency will deviate below the specified limits and when generation is greater than demand, frequency will go beyond nominal value. Therefore, in order to stabilize the demand and frequency variation, generation would be controlled such that a frequency should not deviate beyond the defined limits and similarly tie-lines flows remains in the determine constraints. These objectives are achieved by fine-tuning the load frequency controllers. An enormous number of techniques have been proposed for fine-tuning load frequency controllers.

A PID controller with fractional order technique has been considered for aiding automatic generation control in a single area consisting of thermal generation units. The results indicated that the proposed fractional order technique PID enhanced based AGC controller offers substantial enhancement in the system dynamic response related to the conventional integer order controllers [4]. Hydro power system's dynamics are significantly affected by its head. LFC of high, medium and low head based on PSO in a single-area hydro power system has been presented in [5].

PID parameters tuning using modified particle swarm optimisation has been implemented in single-area load frequency control and results compared with original PSO. The results depicted better dynamic response for modified PSO compared to original PSO [6].

$\mathrm{ABC}$ artificial intelligence algorithm was implemented in [7] for finest tuning of PID controller parameters for a controlling frequency deviations in single unit and multi-units interconnected power system. ABC algorithm is perfect in conducting both local and global search in every iteration and hence has the highest chance of finding the optimum parameters. This also efficiently avoid local best as much as possible.

Moreover, Backstepping method was integrated with GSA for nonlinear system controller design and the performance was evaluated by comparison analysis with PSO incorporated backstepping method [8]. The backstepping technique permits to achieve global stability in the circumstances when the feedback linearisation technique only secures local stability.

GSA was introduced for parameter tuning of PI and PID controllers for frequency control in single unit interconnected power system [9]. The results of simulation clearly depicted that GSA tuned PI and PID controllers provided a superior oscillations control as compared to conventional PI controller in the power system.

However, meta-heuristic optimisation based on BFO and PSO is implemented to define the optimal estimation of the PID controller especially for the demand fluctuation and frequency control. Considering settling time, transient and overshoot analysis, it can be clearly stated that PID tuning by BFO method is superior than PSO method and conventional PI controller [10].

Fuzzy logic based LFC design for two area system is found to be appropriate [11]. But the pure fuzzy rule based expert structures have some disadvantages: It is tough to acquire data, there is no adaptability and therefore for the dynamic time varying system, and it is unable to perform well due to changes in system. An LFC method that has the ability to withstand demand side power fluctuation but with higher performance with regard to dynamic response has been introduced. This approach uses Active Disturbance Rejection Control (ADRC) with two-layer technique that compensates Estimated Equivalent Input Disturbances (EID) for a multi-region interconnected power system [12]. This method performed better than traditional ADRC.

A Battery Energy Storage Systems (BESS) was proposed in [13] for two-area reheat thermal units LFC. BESS gives better results than the conventional PI and PID controllers in terms of frequency deviation and settling time. Superconducting Magnetic Energy Storage (SMES) Systems for enhancement of stability and system dynamic response for multiple interconnections was proposed in [14]. Ability to restore current is the trade mark of SMES unit. Period for current restoration is slow and as such requires artificial enhancement to accelerate the rate of current restoration. PID controller with Seeker Optimisation Algorithm which based on frequency is developed to eliminate power system oscillations due to its capabilities in solving difficult practical optimisation problems in multiple power interconnections [15].

Moreover, according to [16], optimal tuning of LFC controllers is efficient when the LFC controller is designed as many-objective optimisation as compared to single objective. When PSO is used to optimally tunned PID controller for two area interconnections power system, it renders the system robust with ease of execution, stable convergence characteristics and also very good computational performances efficiency [17]. Hybrid PSO 
and GSA (PSOGSA) has improved performance when used for tunning PID controller for Automatic Voltage Regulation system (AVR) in two area-power system [18].

Moreover, a PI controller with GSA algorithm for AGC of an interlocked power system was proposed in [19]. Superiority over modern heuristic optimisation methods such as BFO algorithm and GA-based PI controller for the same interrelated power system was achieved with GSA optimized PI controller. GSA further performed better than PSO and GA in priority based optimisation of PID controller for voltage regulation system [20]. ALFC of two-area power systems using PID tuning through Internal Model Control (IMC) technique has been proposed in [21]. The PID-IMC controller has the ability to provide high adaption for changing conditions and the ability to make quick decisions. The PID-IMC controller is capable of increasing the dynamic response and also bringing the steady state error to a tolerable limit.

Efficient demand and frequency controller in two area power system interconnections has been designed. PSO algorithm was used to optimise PID controller and performed better when results were compared with traditional Ziegler-Nichols PID method [22].

GSA method has been used to obtain optimal parameters of dual PI controller in a two area interconnected power system. Simulation results emphasised that the considered dual PI-based GSA is unique in its operation and provides excellent damping for frequency and tie line power deviation related to conventional PI controller [23]. GSA Optimised Fuzzy-PID controller design for LFC of an interconnected multi-area power system was presented in [24]. Two-area interconnected reheat thermal system was considered with ITAE as an objective function.

However, a comparison between Levenberg Marquardt trained neural controller and PI controller in terms of frequency response under load perturbation was conducted [25]. The technique was tested on two area power interconnections and the neural controller performs better with its maximum overshoot, settling time and its ease of realisation but has a very complex error computation making it sluggish with low convergence rate.

LFC controller design tuning with PSO for controlling frequency deviation in multi area interconnections has been presented in [26]. Results of the Simulation prove that the considered PSO based PID controller provides better transient response and system steady state stability for frequency and also tie line power variation compared to Zeigler-Nichols tuned PID controller but the PSO algorithm has issue with premature convergence, hence affecting the solution in a complex network.

Power system transient response has further been studied with PID controller optimized with fuzzy-logic for demand and frequency fluctuation of three area thermal interconnected power systems [27]. The system was subjected to $1 \%$ perturbation and the controller reacted to suppress the frequency deviations within permissible limit.

In [37] Muthubalaji et.al discussed integrated optimization technique to reduce total cost in RDS by optimally placing the DSTATCOM

Ant Lion Optimizer (ALO) which is inspired by environment has also been utilized to obtain optimised parameters of PI controller for controlling frequency deviations in three-area interconnected power systems [28]. ALO performance was evaluated by doing comparative analysis of the results with Genetic Algorithm and other nature inspired algorithm such as PSO algorithm and Bat Algorithm and performed better with settling time.

The review described various non-linearities in the system models to create it more accurate and at the same time hybrid approaches were used to improve new intelligent control schemes. Settling time and maximum overshoot still remains a bigger challenge to LFC designs which has attracted the attention of researchers to bring those values to minimal as possible. Critical look at the review further depicts that, the complexity of interconnected systems has influence on the controller design. Since a complex power network is easily prone to dynamics and system instabilities associated with catastrophic event on the interconnected system, a more optimal controller is needed to sustain the power system stability.

Hence, this paper presents a new meta-heuristic, nature inspired optimisation tool called the Gravitational Search Algorithm to provide tuning for PID controller (GSA-PID) to achieve optimal parameter tuning for LFC design of a complex four-area interconnected power system. This robust controller model has the capability to improving the settling time and minimising the percentage overshoot of transient and dynamic oscillations.

\section{Designing Gsa Tuned Pid Controller}

In this design, the conventional PID tuning is enhanced using GSA for LFC design to obtain better settling time and lesser maximum overshoot of the power system under investigation. 


\subsection{Design Of Conventional PID Controller}

A Proportional-Integral-Derivative (PID) controller is generally employed to improve the control of dynamic behavior of control structures and to minimize the system imbalances in industrial plants [30]. It has gained popularity commercially because of its simplicity and also excellent performance in wide range of working conditions. A standardized PID controller is a three term controller. As indicated in Eq. (1), the transfer function of PID can be written in parallel form.

$$
\mathrm{PID}_{\text {parallel }}=\mathrm{K}_{\mathrm{P}}+\mathrm{K}_{\mathrm{I}} \frac{1}{\mathrm{~s}}+\mathrm{K}_{\mathrm{D}} \mathrm{S}\left(\frac{1}{\mathrm{~T}_{\mathrm{f}} \mathrm{s}+1}\right)
$$

where, $\mathrm{T}_{\mathrm{f}}=$ derivative filter time constant;

$$
\begin{aligned}
& K_{P}=\text { the controller's proportional gain; } \\
& K_{I}=\text { the gain of the integral term; and } \\
& K_{D}=\text { the gain of the derivative term. }
\end{aligned}
$$

Overall control action is provided by the Proportional term relative to the error signal over all pass gain factor. To minimised the impact of steady error, the integral term is used. Momentarily fault response in powers systems and industrial plants can be efficiently improve with Derivative term over high frequency compensation using a differentiator.Figure 1 illustrates the standard PID controller structure.

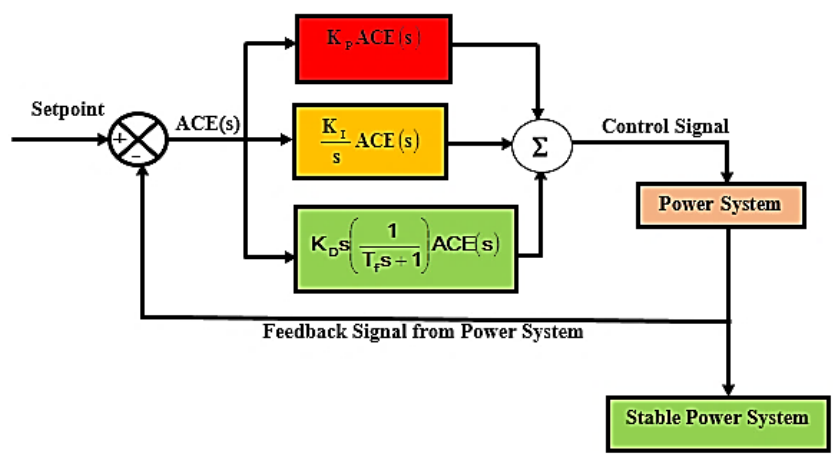

FIGURE 1. Design of PID controller structure.

\subsection{Concept of Gravitational Search Algorithm}

Optimisation problems are widely encountered in various fields in Science and Technology. GSA is one of the newly developed stochastic optimisation techniques with many attractive features. It is motivated by Newton's gravitational and motion law. Early experimentations of employing GSA in many applications in science and technology has indicated its promising potential [31]. The benefits of GSA reported in [9] for example ability to avoid local optima solution, capability to escape from the local optima, enhanced adaptive learning rate, small memory for the algorithm, rate of convergence and ease of implementation, informed the choice of GSA as the best optimisation algorithm for this research work. The algorithm can be presented in steps as shown in the following steps.

Step 1: Initialisation

When a system has $\mathrm{N}$ number of agents, the possible location of the $i^{\text {th }}$ agent within a defined search space represent a suitable answer to the problem. The agent is defined by Eq. (2):

$$
X_{i}=\left(x_{i}, \ldots, x_{i}^{d}, \ldots, x_{i}^{n}\right) \text { when, } i=1,2, \ldots, N(2)
$$

where, $\mathrm{n}=$ size of the problem; and

$x_{i}^{d}=$ location of the $i^{\text {th }}$ agent in the $d^{\text {th }}$ dimension.

Step 2: Assessment of Fitness for all Agents 
At every step, there should be execution of all agents and agents that has bad fitness are further computed for every iterations described according to the minimization problem in Eq. (3) and Eq. (4) respectively:

$$
\begin{aligned}
\operatorname{best}(t) & =\min _{J \in\{1, \ldots, N\}} f i t_{j}(t) \\
\operatorname{worst}(t) & =\max _{J \in\{1, \ldots, N\}} f_{i t}(t)
\end{aligned}
$$

where, fit $_{j}(t)$ represents fitness of $j$ th agent in iterations $t$;

best $(\mathrm{t})$ minimum fitness estimation of all agents; and

worst $(\mathrm{t})$ maximum fitness value of all agents.

\section{Step 3: Estimation of Constant Gravit}

The main function of gravitational constant is to adjust the precision of the search and so minimised with time. The constant of gravity at a given iteration $\mathrm{t}, \mathrm{G}(\mathrm{t})$ can be computed as in Eq. (5):

$$
G(t)=G_{o} e^{\left(-\alpha \frac{1}{T}\right)}
$$

where, $G_{0}=$ an assumed value taken at random to represent initial value of the gravitational constant

$$
\begin{aligned}
& \alpha=\text { a constant determined by the user; } \\
& \mathrm{t}=\text { present iteration; and } \\
& \mathrm{T}=\text { maximum or the total number of iterations. }
\end{aligned}
$$

Step 4: Gravitational mass and Inertia Mass should be updated for better performance in each iteration as in Eq. (6), Eq. (7) and Eq. (8) respectively:

$$
\begin{gathered}
\mathrm{M}_{\mathrm{ai}}=\mathrm{M}_{\mathrm{pi}}=\mathrm{M}_{\mathrm{ii}}=\mathrm{M}_{\mathrm{i}}, \quad \mathrm{i}=1,2, \ldots, \mathrm{N} \\
\mathrm{m}_{\mathrm{i}}(\mathrm{t})=\frac{\operatorname{fit}_{\mathrm{i}}(\mathrm{t})-\operatorname{worst}(\mathrm{t})}{\operatorname{best}(\mathrm{t})-\operatorname{worst}(\mathrm{t})}
\end{gathered}
$$

where, fit $_{\mathrm{i}}(\mathrm{t})$ is the fitness of the $\mathrm{i}^{\text {th }}$ agent in iteration $\mathrm{t}$.

$$
M_{i}(t)=\frac{m_{i}(t)}{\sum_{j=1}^{N} m_{j}(t)}
$$

where, $M_{a i}=$ active mass relating to gravity of the $i^{\text {th }}$ agent;

$$
\begin{aligned}
& M_{p i}=\text { passive mass relating to gravitaty of } i^{\text {th }} \text { agent; } \\
& M_{i i}=\text { mass relating to inertia of the } i^{\text {th }} \text { agent; and } \\
& M_{i}(t)=i^{\text {th }} \text { agent with mass at iteration } t \text {. }
\end{aligned}
$$

Step 5: Compute the Total Force

The sum of forces impacting on the $\mathrm{i}^{\text {th }}$ agent can be calculated as in Eq. (9):

$$
\mathrm{F}_{\mathrm{i}}^{\mathrm{d}}(\mathrm{t})=\sum_{\mathrm{j} \in \text { Kbest } j \neq i} \operatorname{randj}_{\mathrm{ij}}^{\mathrm{d}}(\mathrm{t})
$$

where, randj $=$ represent numbers taken at random with interval [0,1]; and

Kbest $=$ all the $\mathrm{K}$ agents with the best fitness value and biggest mass.

Again, a force that dwells on the $i^{\text {th }}$ mass $\left(m_{i}(t)\right)$ from the $j^{\text {th }}$ mass $\left(M_{j}(t)\right)$ at the specific iterations $t$, can be defined by gravitational theory as in Eq. (10): 


$$
F_{i j}^{d}(t)=G(t) \frac{M_{p i}(t) \times M_{a j}(t)}{R_{i j}(t)+\varepsilon}\left(x_{j}^{d}(t)-x_{i}^{d}(t)\right)
$$

where, $\mathrm{R}_{\mathrm{ij}}(\mathrm{t})=$ Euclidian distance between $\mathrm{i}^{\text {th }}$ and $\mathrm{j}^{\text {th }}$ agents; and $\varepsilon$ is the small constant.

$$
R_{i j}(t)=\left(\left\|X_{i}(t), X_{j}(t)\right\|_{2}\right)
$$

where, $X_{\mathrm{i}}$ and $\mathrm{X}_{\mathrm{j}}$ are the positions of agent $\mathrm{i}$ and $\mathrm{j}$.

Figure 2 illustrates the interactions among masses (m) within a search space and the combination of forces acting over an object and its acceleration (a).

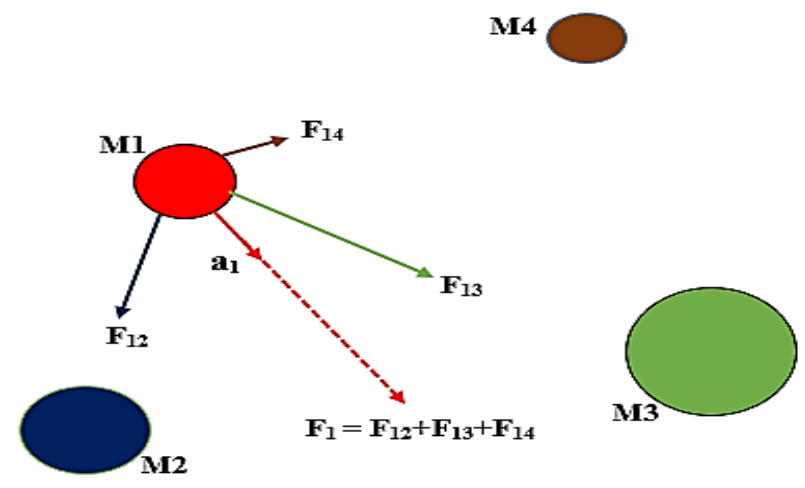

FIGURE 2. Sum of forces acting on an object.

Step 6: Acceleration and Velocity Estimation

The velocity and acceleration of the $i^{\text {th }}$ agent at iteration $t$ in $\mathrm{d}^{\text {th }}$ dimension are estimated using law of gravity and law of motion as in Eq. (12) and Eq. (13) respectively:

$$
\begin{aligned}
& a_{i}^{d}(t)=\frac{F_{i}^{d}}{M_{i i}} \sum_{j \in k b e s t_{j} \neq i} \operatorname{rand}_{j} G(t) \frac{M_{j}(t)}{R_{i j}(t)+\varepsilon}\left(x_{j}^{d}(t)-x_{i}^{d}(t)\right) \\
& v_{i}^{d}(t+1)=\operatorname{rand}_{i} \times v_{i}^{d}(t)+a_{i}^{d}(t)
\end{aligned}
$$

where, $\mathrm{a}_{\mathrm{i}}(\mathrm{t})=$ acceleration of $\mathrm{i}^{\text {th }}$ agent at iteration $\mathrm{t}$;

$$
\begin{aligned}
& \mathrm{V}_{\mathrm{i}}(\mathrm{t})=\text { velocity of ith agent at iteration } \mathrm{t} \text {; and } \\
& \text { Rand }_{\mathrm{i}}=\text { uniform random variable within the interval }[0,1] .
\end{aligned}
$$

Step 7: Update the Location of Agents

What the algorithm does at this stage is to find the successive velocity and next location of the agent. The next velocity of the agent implies a function of the current velocity added to the current acceleration. The velocity and acceleration are recomputed as in Eq. (14):

$$
x_{i}^{d}(t+1)=x_{i}^{d}(t)+v_{i}^{d}(t+1)
$$

Step 8: Repeating the Steps for Iteration

At this stage, the algorithm repeats all the stages until the conditions set for convergence are met. At the last stage of the iteration, the value of locations of corresponding agent at particular dimension is returned. This value indicates the global solution of the optimisation problem. All the steps above explained the working principle of the GSA. Flow chart of the algorithm is illustrated in Figure 3 [31].

The criteria for measuring performance of a good controller is the selection of a good objective function. Fitness function used for this research is the Integral of Time multiplied Absolute Error (ITAE) performance criterion. Minimal overshoots and smaller oscillations during unstable condition, being the major advantage of 
ITAE performance index over Integral of Absolute Error (IAE) and Integral Square Error (ISE) performance indices demonstrates why it was chosen for this research work. The objective function is defined in Eq. (15).

$$
J=I T A E=\int_{0}^{t} t\left|\operatorname{ACE}_{i}(t)\right| d t
$$

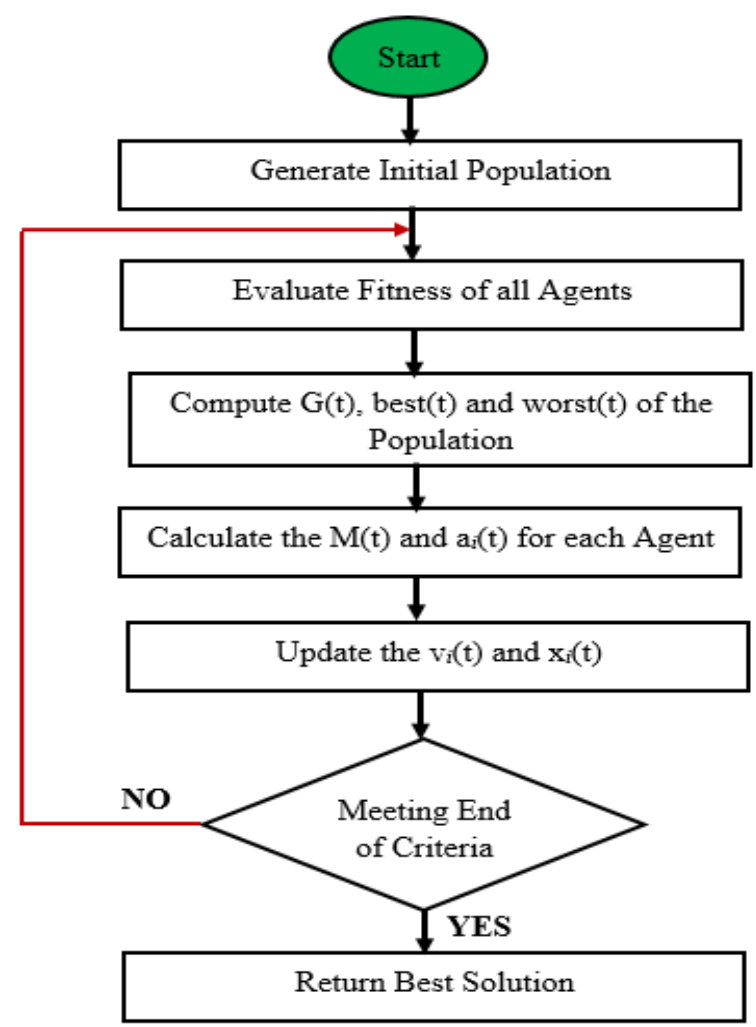

FIGURE 3. Flow chart of gravitational search algorithm.

\subsection{Integrating GSA-PID Controller}

This section explains the development GSA-PID controller. The GSA algorithm will search for optimum value for PID controller parameters $K_{P}, K_{I}$ and $K_{D}$. Every member of $K$ contains three controller measures $\left(K_{P}, K_{I}, K_{D}\right)$. The structure of GSA techniques in PID controller tuning can be visualised in Figure 4. The searching process of proposed GSA-PID controller is shown in a flow chart illustrated in Figure 5. This demonstrates the proposed control method. PSO algorithm is incorporated the same way as the GSA for analysis.

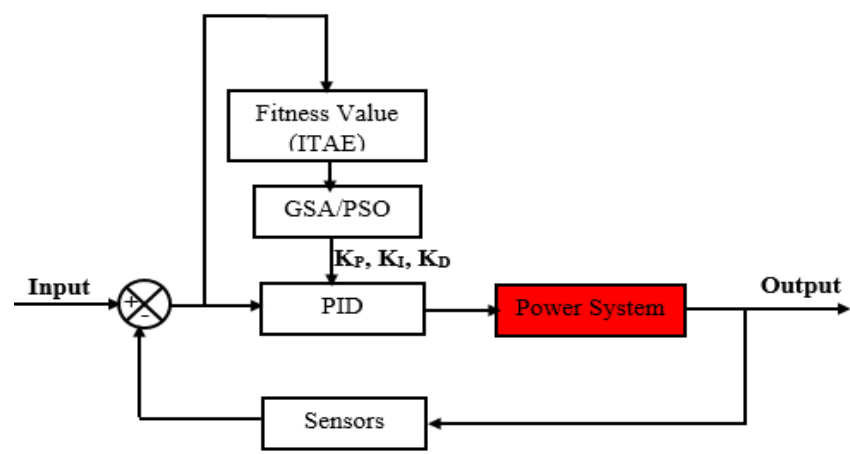

FIGURE 4. Block representation of GSA-PID controller. 


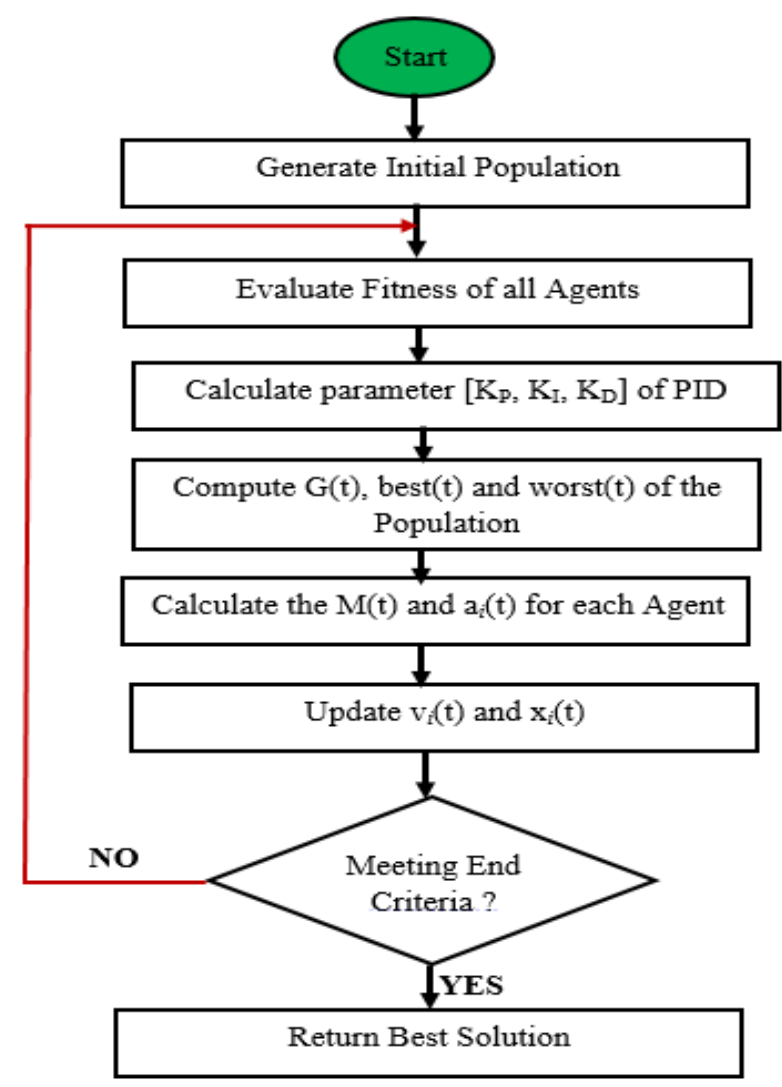

FIGURE 5. Flow chart of GSA-PID control system.

\section{- Implementation Of Gsa-Pid Controller On Four Area Interconnected Power System}

This section focuses on the dynamic models of LFC for a four-area interrelated power system and the actual implementation of the GSA-PID controller on the proposed power system.

\subsection{Power System under Investigation}

The power network studied consists of four generating regions of equal sizes. Region 1 and Region 2 are reheat thermal systems and Region 3 and Area 4 are hydro generating plants. Figure 6 shows the transfer function model of a four-area hydro-thermal system. The thermal plant has a reheat mechanism enhancing the efficiency of the thermal generation system. The hydro plant has speed regulation mechanism called hydraulic governor responsible for maintaining frequency within permissible limit under demand fluctuation. A bias setting of $\beta$ is measured in both hydro and thermal areas. The optimal values of derivative, proportional in addition integral gains for the LFC have been achieved by ITAE criterion. 1\% and 5\% step load disturbances is considered in one of the areas. It is very essential to optimise the LFC parameters carefully, or else improper selection of these measures will lead to system instability [32].

Introduction of Tie-line bias control is to ensure that steady state stability is maintained. This implies that, it is a share responsibility of every active connected area to contribute its own quota in maintaining frequency constant and also correct power variations within its interchange.The area control error is the input to the controller. Hence, the ACE in $\mathrm{i}^{\text {th }}$ area is given in Eq. (16);

$$
\mathrm{ACE}_{\mathrm{i}}=\beta \Delta \mathrm{f}_{\mathrm{i}}+\Delta \mathrm{P}_{\text {tie-Line }}
$$

However, the control errors in the four areas is presented in Eq. (17) to (20).

$$
\mathrm{ACE}_{1}=\beta_{1} \Delta \mathrm{f}_{1}+\Delta \mathrm{P}_{12}
$$

FIGURE 6. Modeling of the four-area interconnected power system. 


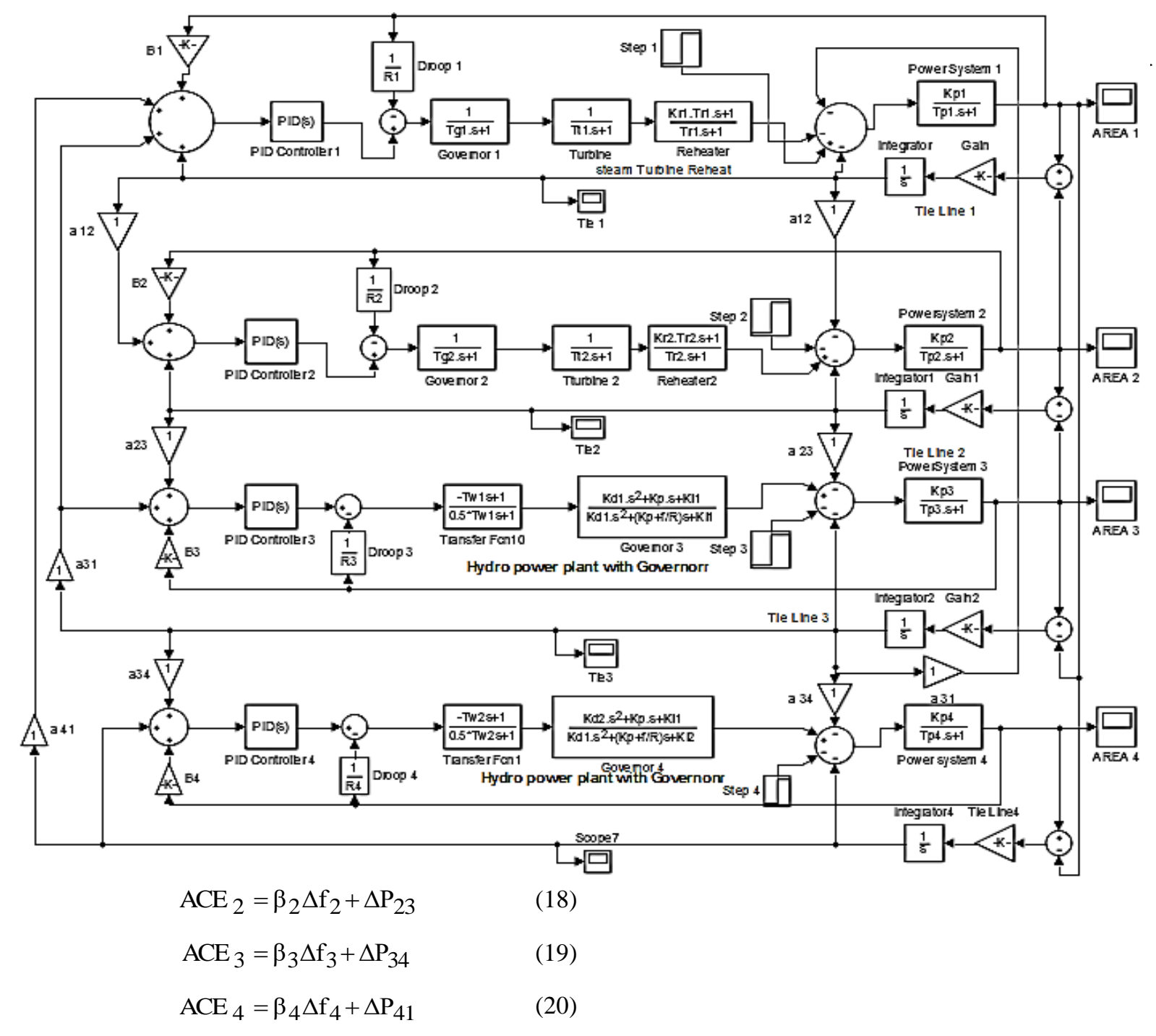

where, ACE Area Control Error of area 1, 2, 3 and 4;

$\beta=$ frequency biasing factor of area $1,2,3$ and 4 ;

$\Delta \mathrm{f}=$ frequency change in area $1,2,3$ and $4 ;$

$\Delta \mathrm{P}_{12}$ tie line power exchange between region $1 \& 2$;

$\Delta \mathrm{P}_{23}=$ tie line power interchange between region 2 and 3;

$\Delta \mathrm{P}_{34}$ tie line power interchange between region $3 \& 4$;

$\Delta \mathrm{P}_{41}$ tie line power interchange between region $4 \& 1$.

\subsection{System Modelling}

The transfer function modeling showing dynamic design of demand and frequency stability controller for power interconnections made up four areas is illustrated in figure 6 . When a system is comprises of several areas interconnected, every area has a complete generation unit consisting of speed governor mechanism, turbine and generator. Each area has both inputs and output data yielding input and output results. The optimised parameters of controller, $\Delta \mathrm{P}_{\text {ref }}$, load imbalances $\Delta \mathrm{P}_{\mathrm{D}}$ and deviation in tie-line power error $\Delta \mathrm{P}_{\text {tie. }}$. Generator frequency $(\Delta \mathrm{f})$ and area control error (ACE) are the outcomes.

\subsection{Parameters used in Four-Area Power System Model}

Nominal values of parameters used in the power system model are presented in Table A1 of Appendix A. Parameters from Volta River Authority (VRA), Ghana being a generating station were computed to obtain the power system constants for this model. This data is also used by several researchers as basic material for research in investigating the stability and designing load frequency control for complex power system network [33], [34], [35], [36]. 
For the parameter selection for GSA-PID controller in this evaluation, it was set to $\mathrm{N}=30$, itermax $=50, \mathrm{~d}=$ 12 which denoted proportional gain $(\mathrm{Kp})$, integral gain $(\mathrm{Ki})$, and derivative gain $(\mathrm{Kd})$ for the four controllers, Go $=100, \alpha=15$ and $\varepsilon=10$. The same iteration number and population size was used for the PSO-PID. Conventional PID parameters were chosen as $\mathrm{Kp}=0.1341, \mathrm{Ki}=0.6, \mathrm{Kd}=0.15$ [22].

\subsection{Implementation of GSA-PID Controller on Four Area Power System}

Figure 7 illustrates the proposed method of implementation on the four-area interconnected power system. Mathematical modelling of GSA algorithm is converted into MATLAB codes and implemented on the system through a MATLAB function block in Simulink

\section{Results And Discussions}

The simulation results presented in this section was carried out in MATLAB/Simulink version R2016a on AMD E1-2100 APU, 1.0 GHz processor, 64-bit, 4.0 GHz operating system. The optimisation algorithm is described in .m file and the simulation run in MATLAB. The tuning of the PID parameters by the optimisation algorithm was done by executing the program 50 times and then the optimal values of the fitness function was obtained. It was realised that population size 30, gravitational constant 100 and acceleration constant 15 gives the best optimal value.

\subsection{Frequency Response Under $1 \%$ Step Load Change}

The developed method is utilised to obtain optimal parameters of the PID controller. Figure 8 to Figure 11 shows frequency response of the four-area power system after being subjected to a $1 \%$ step load change. The three separate graphs on the plots represent control actions of the three controllers. A load variation of $1 \%$ in the power system implies a sudden load change in the area 1 . Sudden load changes create frequency oscillations which are diminished with time to normalise the system stability. It could be observed from Figure 8 to Figure 11 that, with GSA-PID Controller, Area frequency deviations settle rapidly and the dynamic responses are minimum oscillatory with low amplitude of peak overshoots in area 1. In interconnected systems, disturbances in an area affects the other interconnected areas. Figure 9, Figure 10 and Figure 11 depict the frequency response due to $1 \%$ load perturbation in area 1. GSA-PID controller illustrated better frequency responses in area 2, area 3 and area 4 as compared to PSO-PID controller and classical PID controller

The settling time in all the areas produced tremendous results with GSA-PID controller which is $5.96 \mathrm{~s}, 5.3 \mathrm{~s}$, $8.69 \mathrm{~s}$ and $7.88 \mathrm{~s}$ in power area 1, power area 2, power area 3 and power area 4 respectively as compared to PSOPID and Conventional PID showing in Table 2. Again, GSA-PID produced less percentage overshoot (\%OS), $6.66 \%, 0.40 \%, 38.85 \%$ and Conventional PID performed poorly in terms of percentage $5.31 \%$ in area $1,2,3$ and 4 respectively as shown in Table 1. Conventional PID performed poorly in terms of percentage overshoot and settling time in all the areas. Table 3 illustrates the optimised PID parameters obtained from GSA, PSO and Ziegler-Nichols tuning method.

Figure 12 to Figure 15 also indicate the tie-line power deviations of the four areas. PSO-PID controller attempted to restore the tie-line power initial state but was not satisfactorily and even worse in the case of Conventional PID controller. The tie line power deviations in Figure 12 to Figure 15 settles at approximately zero steady state errors with GSA-PID. This simply means that, GSA-PID controller has the capability of damping the transient oscillations within a shortest possible time as compared to PSO-PID and conventional PID controllers.

\subsection{Sensitivity and Robustness Analysis of GSA-PID Controller for Different Load Deviations}

The sensitivity analysis of GSA-PID controller is performed to verify the robustness of the optimised GSAPID gain parameters, which is achieved at nominal case. The disturbance is generally associated with the interrelated system. So whichever controller designed at nominal case should be robust sufficient to handle the disturbance. This will be done by changing the magnitude and also position of step load change in the system. In this case 5\% load change applied to the four-area system is considered in the system for sensitivity analysis. Figure 16 to Figure 19 represent frequency response of the four-area system after 5\% load increment. Figure 20 to Figure 23 are tie-line power variations of the interconnected systems. 


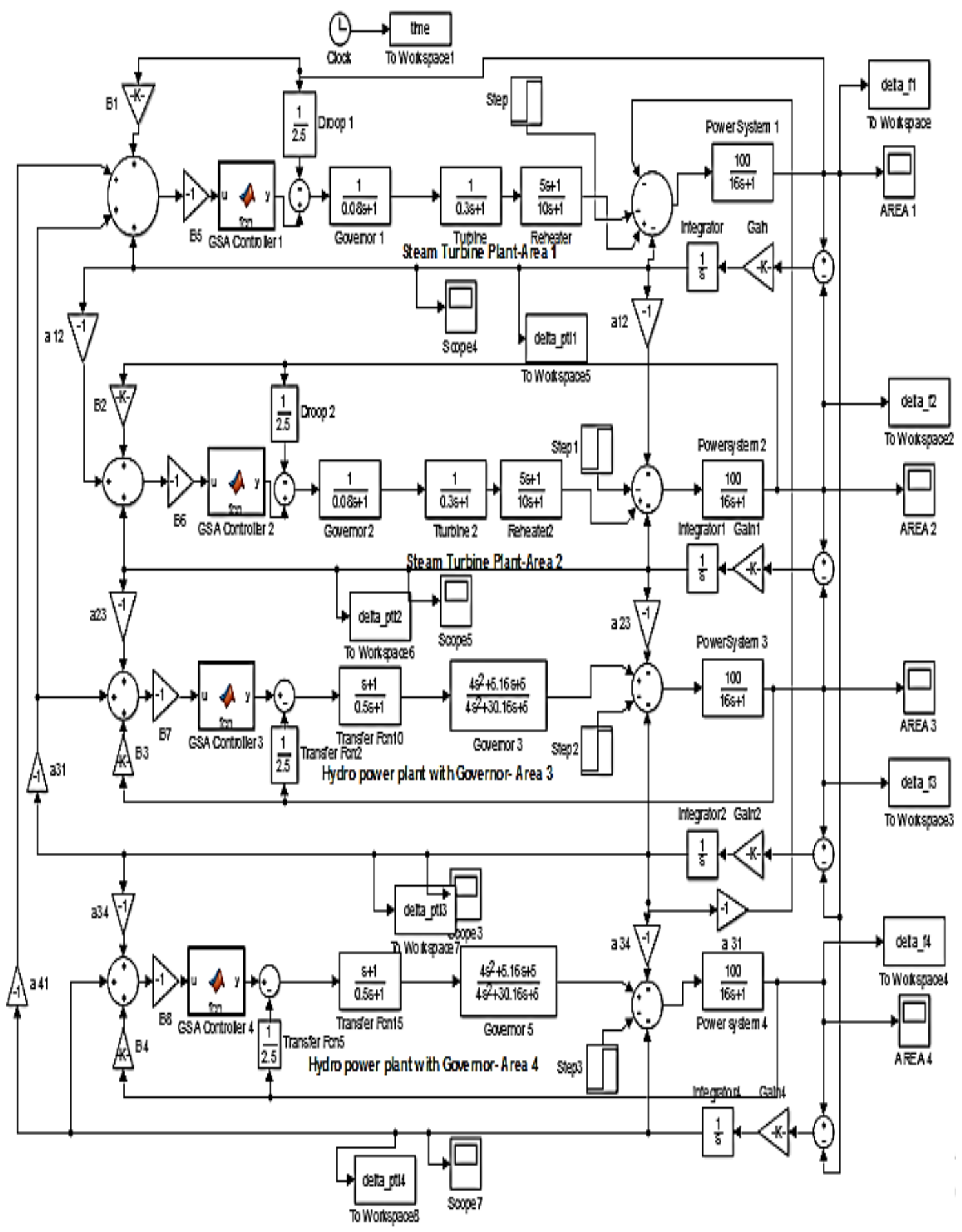

FIGURE 7. Simulated diagram of four-area power system with GSA-PID controller. 


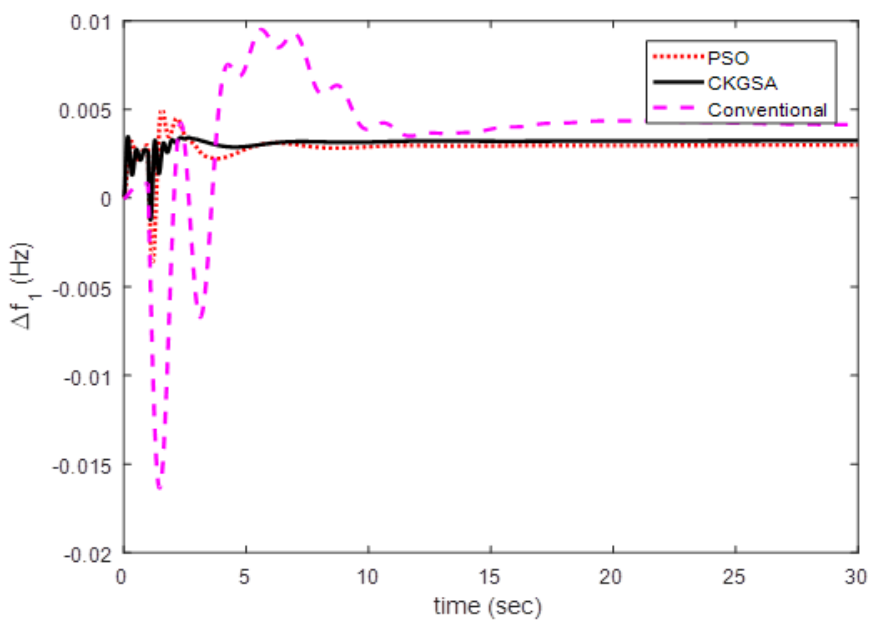

FIGURE 8. Frequency change in

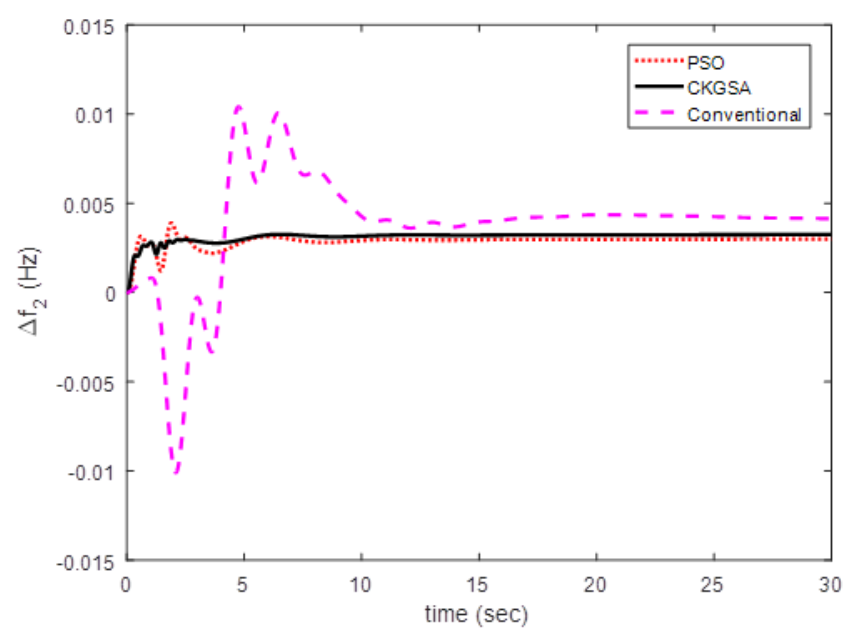

FIGURE 9. Frequency change in area 2 (Thermal Plant).

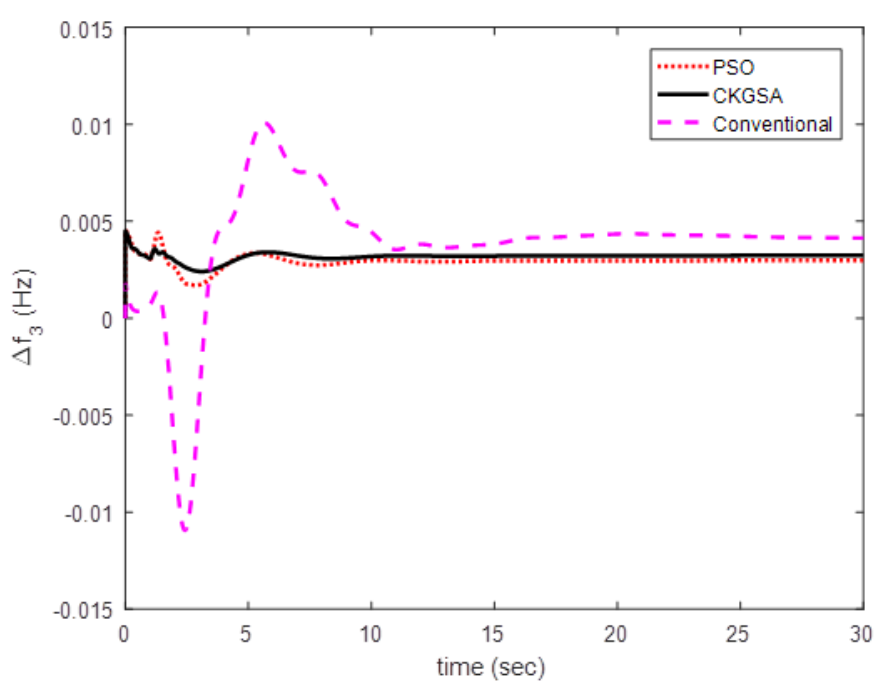

FIGURE 10. Frequency change in area 3 (Hydro Plant) 


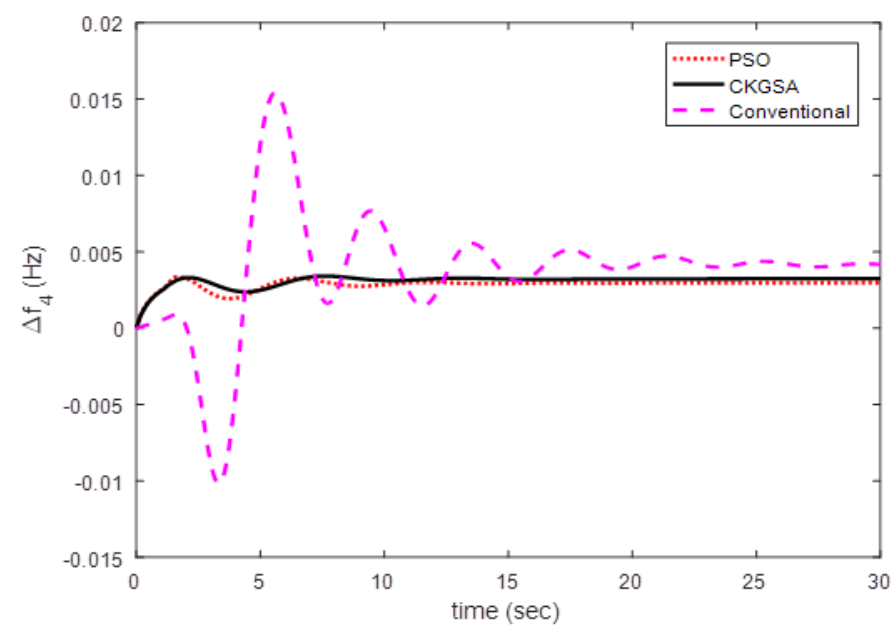

FIGURE 11. Frequency change in area 4 (Hydro Plant

TABLE 1. Peak overshoot with $1 \%$ step load change in the four-area power system.

\begin{tabular}{|l|l|l|l|l|}
\hline $\begin{array}{l}\text { Controller } \\
\text { Type }\end{array}$ & $\begin{array}{l}\text { \%OS } \\
\text { Area 1 } \\
(\%)\end{array}$ & $\begin{array}{l}\text { \%OS } \\
\text { Area 2 } \\
(\%)\end{array}$ & $\begin{array}{l}\text { \%OS } \\
\text { Area 3 } \\
(\%)\end{array}$ & $\begin{array}{l}\text { \%OS } \\
\text { Area 4 } \\
(\%)\end{array}$ \\
\hline PSO-PID & 67.63 & 30.20 & 52.14 & 12.67 \\
\hline GSA-PID & $\mathbf{6 . 6 6}$ & $\mathbf{0 . 4 0}$ & $\mathbf{3 8 . 8 5}$ & $\mathbf{5 . 3 1}$ \\
\hline Conv.-PID & 129.82 & 151.23 & 143.59 & 269.13 \\
\hline
\end{tabular}

TABLE 2. Settling time with $1 \%$ step load change in the four-area power system.

\begin{tabular}{|l|l|l|l|l|}
\hline Controller & $\begin{array}{l}\text { Settling } \\
\text { Time } \\
\text { Area 1 } \\
\text { (Sec.) }\end{array}$ & $\begin{array}{l}\text { Settling } \\
\text { Time } \\
\text { Area 2 } \\
\text { (Sec.) }\end{array}$ & $\begin{array}{l}\text { Settling } \\
\text { Time } \\
\text { Area 3 } \\
\text { (Sec.) }\end{array}$ & $\begin{array}{l}\text { Settling } \\
\text { Time } \\
\text { Area 4 } \\
\text { (Sec.) }\end{array}$ \\
\hline PSO-PID & 9.29 & 9.16 & 8.77 & 9.92 \\
\hline GSA-PID & $\mathbf{5 . 9 6}$ & $\mathbf{5 . 3 0}$ & $\mathbf{8 . 6 9}$ & $\mathbf{7 . 8 8}$ \\
\hline Conv.-PID & 21.79 & 21.38 & 20.93 & 22.32 \\
\hline
\end{tabular}

FIGURE 12. Tie-line power change in area 1 (thermal- thermal).

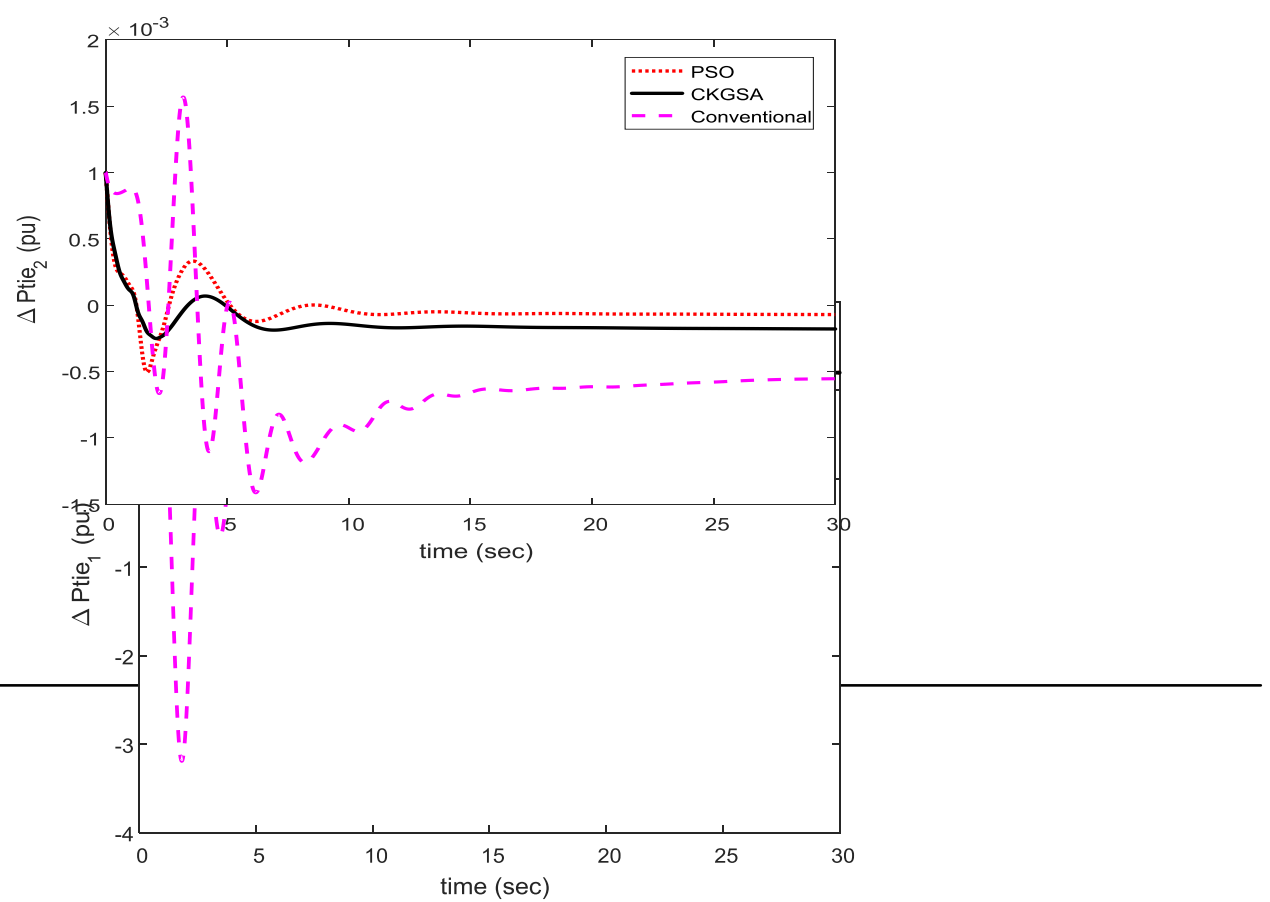


FIGURE 13. Tie-line power change in area 2 (thermal-hydro).

\begin{tabular}{|l|l|l|l|l|l|l|l|l|l|}
\hline \multirow{2}{*}{ Area } & \multicolumn{3}{|l|}{ GSA-PID Controller } & \multicolumn{3}{l|}{ PSO-PID Controller } & \multicolumn{3}{l|}{ Conv. PID Controller } \\
\cline { 2 - 10 } & $\mathrm{K}_{\mathrm{p}}$ & $\mathrm{K}_{\mathrm{i}}$ & $\mathrm{K}_{\mathrm{d}}$ & $\mathrm{K}_{\mathrm{p}}$ & $\mathrm{K}_{\mathrm{i}}$ & $\mathrm{K}_{\mathrm{d}}$ & $\mathrm{K}_{\mathrm{p}}$ & $\mathrm{K}_{\mathrm{i}}$ & $\mathrm{K}_{\mathrm{d}}$ \\
\hline Area 1 & 7.1765 & 1.8354 & 1.3946 & 4.0677 & 6.3149 & 3.1905 & 0.1341 & 0.600 & 0.1500 \\
\hline Area 2 & 3.4821 & 9.9467 & 2.7259 & 2.6341 & 4.5866 & 5.1948 & 0.1341 & 0.600 & 0.1500 \\
\hline Area 3 & 5.753 & 0.0306 & 1.8226 & 5.0770 & 0.0081 & 5.0839 & 0.1341 & 0.600 & 0.1500 \\
\hline Area 4 & 5.3285 & 5.0515 & 4.2817 & 4.1571 & 6.8248 & 5.0092 & 0.1341 & 0.600 & 0.1500 \\
\hline
\end{tabular}

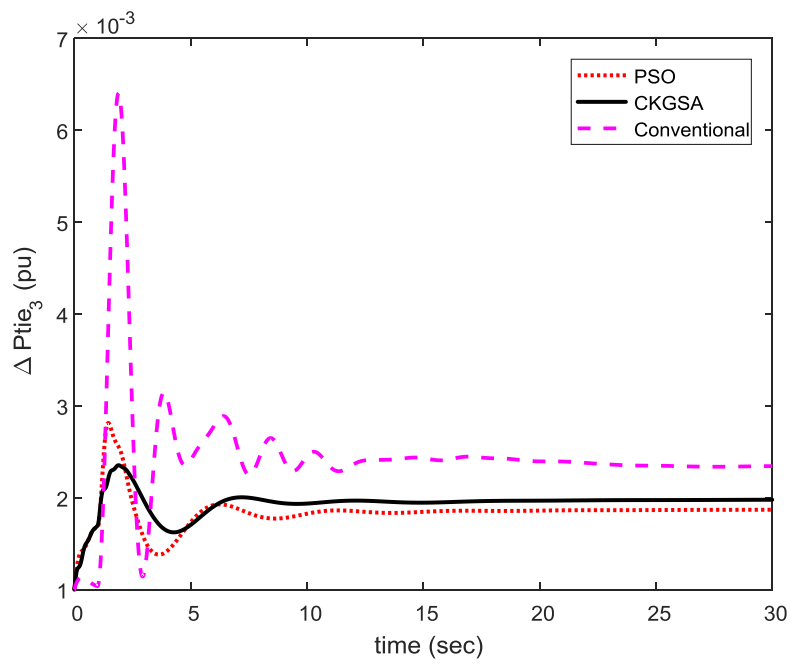

FIGURE 14. Tie-line power change in area 3 (hydro-hydro). 


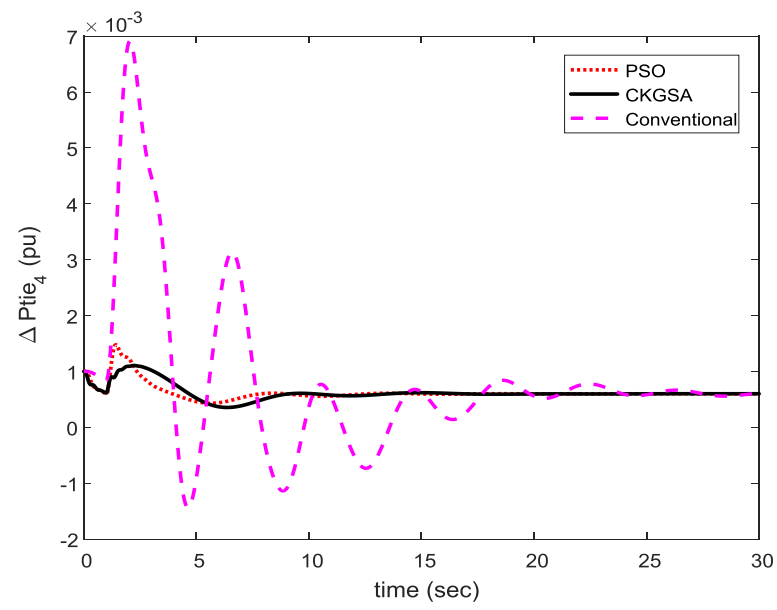

FIGURE 15 Tie-line power change in area 4 (hydro-thermal).

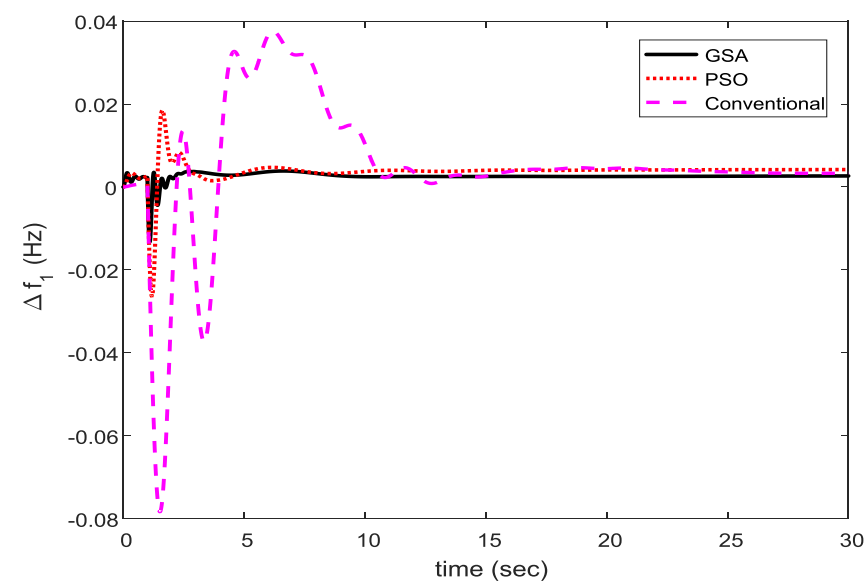

FIGURE 16. Frequency response in area 1 at $5 \%$ change in load.

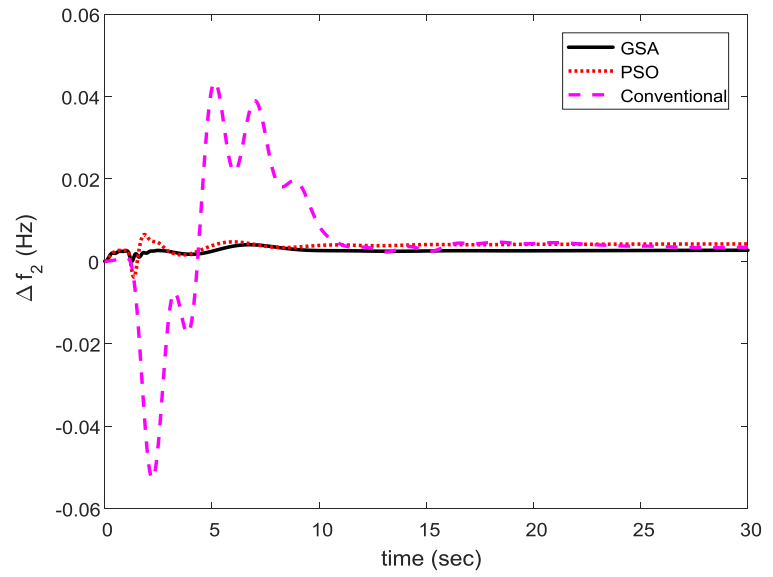

FIGURE 17. Frequency response in area 2 at $5 \%$ change in load 


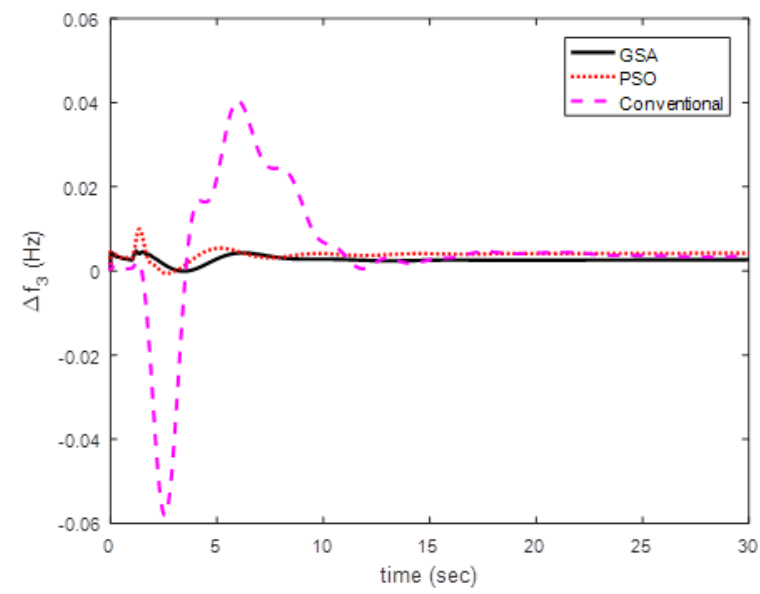

FIGURE 18. Frequency response in area 3 at $5 \%$ change in load.

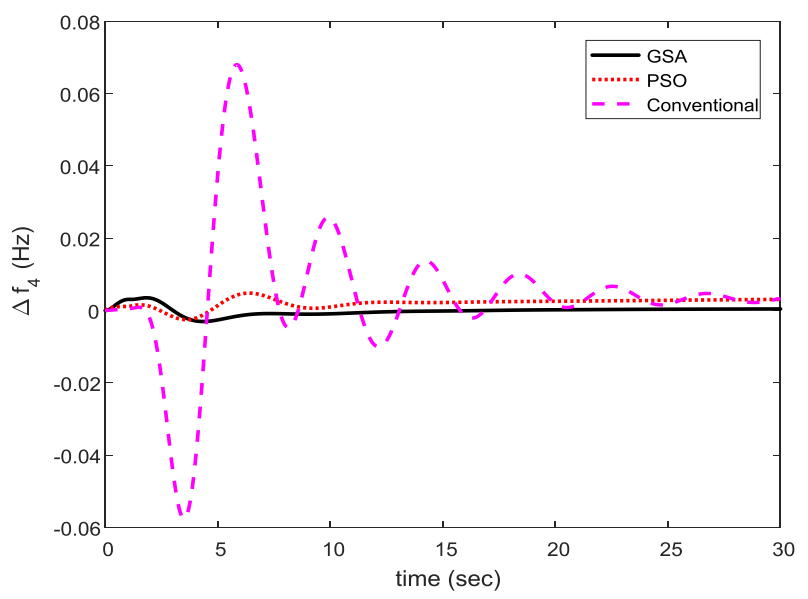

Figure 19. Frequency response in area 4 at $5 \%$ change in load.

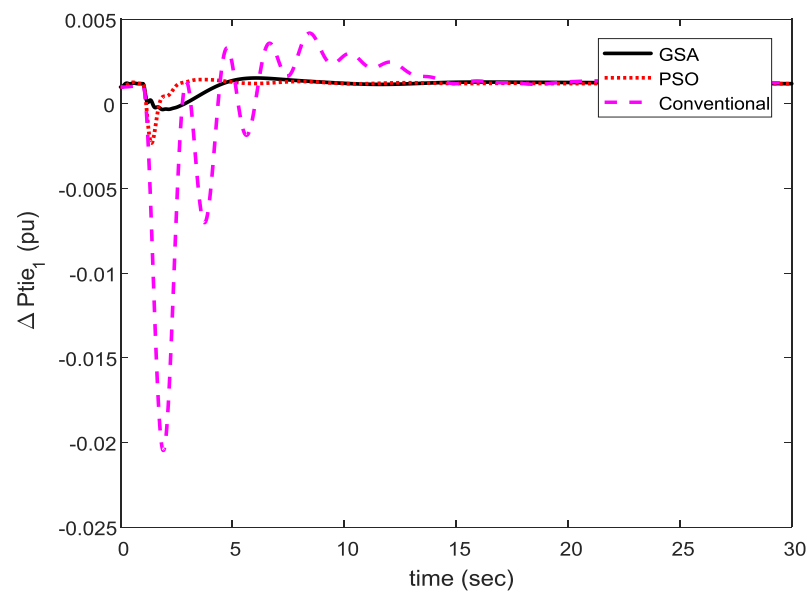

Figure 20. Tie-line response in area 1 at $5 \%$ change in load. 


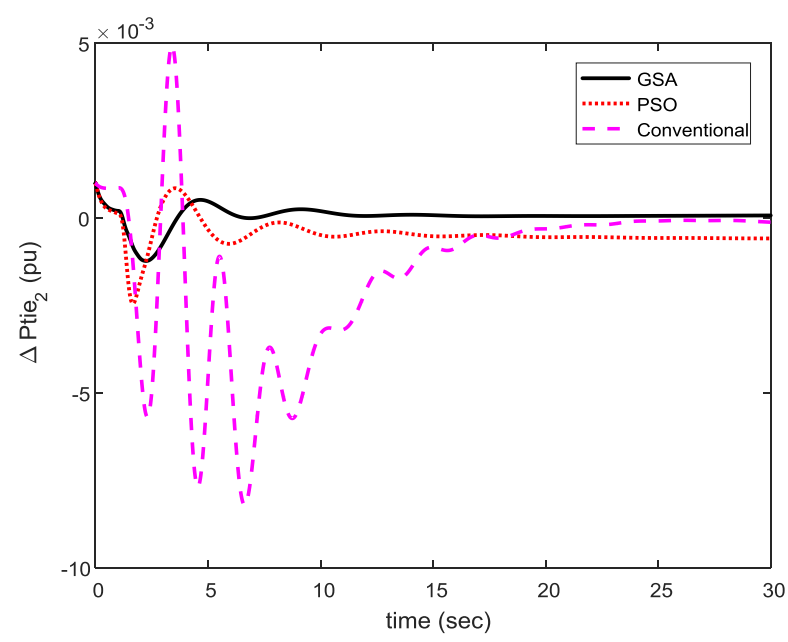

Figure 21. Tie-line response in area 2 at $5 \%$ change in load.

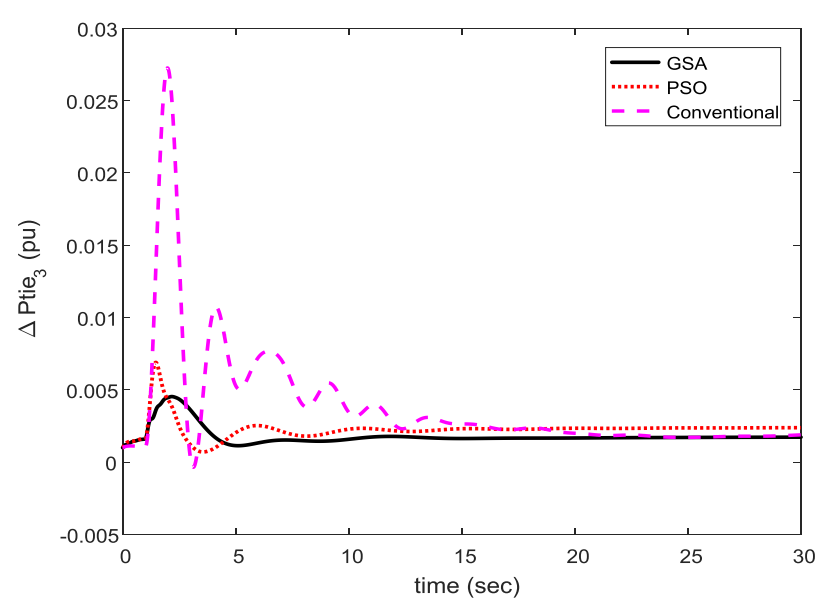

Figure 22. Tie-line response in area 3 at $5 \%$ change in load.

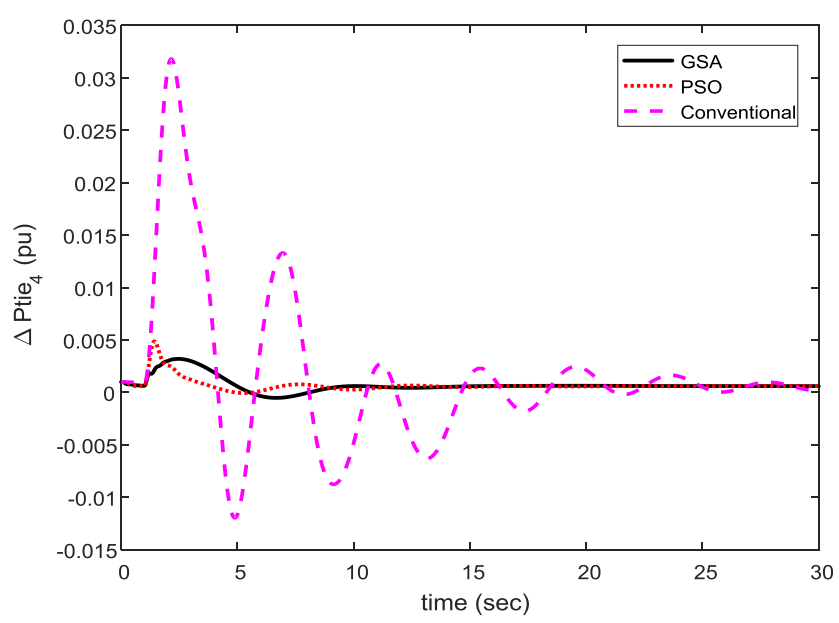

Figure 23. Tie-Line Response in Area 4 at 5\% Change in Load.

Table 4 and Table 5 illustrate the settling time of frequency deviations under the three controllers. It could be observed that, GSA-PID remains robust as compared to PSO-PID and conventional PID controllers under 5\% load deviation in all the areas with fastest settling time and less transient overshoot. 
TABLE 4. Settling time under $5 \%$ step change in load.

\begin{tabular}{|l|l|l|l|l|}
\hline Controller & $\begin{array}{l}\text { Settling } \\
\text { Time } \\
\text { Area 1 } \\
\text { (Sec.) }\end{array}$ & $\begin{array}{l}\text { Settling } \\
\text { Time } \\
\text { Area 2 } \\
\text { (Sec.) }\end{array}$ & $\begin{array}{l}\text { Settling } \\
\text { Time } \\
\text { Area 3 } \\
\text { (Sec.) }\end{array}$ & $\begin{array}{l}\text { Settling } \\
\text { Time } \\
\text { Area 4 } \\
\text { (Sec.) }\end{array}$ \\
\hline PSO-PID & 17.29 & 16.15 & 15.14 & 17.22 \\
\hline GSA-PID & $\mathbf{1 2 . 9 6}$ & $\mathbf{1 2 . 0 3}$ & $\mathbf{1 3 . 6 9}$ & $\mathbf{1 1 . 8 8}$ \\
\hline Conv.-PID & 25.4 & 26.04 & 25.35 & 29.87 \\
\hline
\end{tabular}

TABLE 5. Peak overshoot under 5\% step change in load

\begin{tabular}{|l|l|l|l|l|}
\hline Controller & $\begin{array}{l}\text { \%OS } \\
\text { Area 1 } \\
(\%)\end{array}$ & $\begin{array}{l}\text { \%OS } \\
\text { Area 2 } \\
(\%)\end{array}$ & $\begin{array}{l}\text { \%OS } \\
\text { Area 3 } \\
(\%)\end{array}$ & $\begin{array}{l}\text { \%OS } \\
\text { Area 4 } \\
(\%)\end{array}$ \\
\hline PSO-PID & $\mathbf{1 3 9 . 5 0}$ & $\mathbf{1 2 0 . 1 1}$ & $\mathbf{1 3 6 . 2 1}$ & $\mathbf{1 4 1 . 2 0}$ \\
\hline GSA-PID & $\mathbf{4 4 . 7 6}$ & $\mathbf{5 0 . 1 1}$ & $\mathbf{7 5 . 9 6}$ & $\mathbf{6 5 . 1 2}$ \\
\hline $\begin{array}{l}\text { Conv.- } \\
\text { PID }\end{array}$ & $\mathbf{5 2 7 . 6 4}$ & $\mathbf{5 8 0 . 8 4}$ & $\mathbf{6 6 7 . 8 4}$ & $\mathbf{7 2 1 . 6 5}$ \\
\hline
\end{tabular}

\section{Conclusions}

Power systems continuously experience changes during abnormal operating conditions. This can be attributed to intermittent renewable energy integration, varying generation outputs of generation stations within the interconnected systems and different magnitude of fault occurrences on the network. Controlling such unforeseen occurrence is paramount to Power utility companies in order to achieve stable power system operations. Demand and frequency control is a step in right direction to suppress oscillations emanating as result of mechanical part and electrical part of a power system, efficient damping of oscillations can be achieved and increasing chances of system stability and thereby improving overall stability of the power system. The traditional PID controller is popularly known for controlling SSE of interconnected power. However, the architecture of modern power systems is complex and fragile and possess nonlinear load characteristics with variations in operating conditions. Due to the sophiscated nature of modern power system network, obtaining PID operating parameters with old methods like Ziegler-Nichols, Karl-Astrom, Cohen-coon, Tyreus-Luyben method etc., might not guarantee robust and efficient performance at certain operating conditions in the current architecture of power system network. Hence, the need for fast and robust controller design capable of controlling the dynamics in modern power system. However, an efficient and a robust controller is the one with less overshoot, quickest settling time and capability of effectively damping transient oscillation. GSA-PID controller exhibited all these qualities, hence GSA-PID is the best LFC design for complex multi-area interconnections control.

\section{References}

G. Shahgholian and A. Fattallahi, "Improving Power System Stability Using Transfer Function: A Comparative Analysis", Journal of Engineering, Technology and Applied Science Research, Vol. 1, No. 5, pp. 1946 1952, 2017.

M. Ahmed and N. K. Roy, "A Comparative Analysis on Different Types of Power System Stabilisers", International Conference on Informatics, Electronics and Vision, Dhaka, Bangladesh, India, pp. $797-802$, 2016.

K. K. Vikram, A. Krishian and K. Preeti, "Automatic Generation Control for Interconnected Hydro-Thermal System with the Help of Conventional Controllers", International Journal for Electrical and Computer Engineering, Vol. 2, No. 4, pp. 547 - 552, 2012.

C. Ismail and T. K. Sindhu, "Automatic Generation Control of Single Area Thermal Power System with Fractional Order PID controllers", 3rd International Conference on Advances in Control and Optimisation of Dynamical Systems, Kanpur, India, pp. 552 - 557, 2014. 
A. M. Jadhav, E. T. Toppo and K. Vadirajacharya, "Load Frequency Control Based on Particle Swarm Optimisation in a Single Area Hydro Power System Under Various Heads", IEEE International Conference on Advances in Engineering, Science and Management, Nagapattinam, Tamil Nadu, India, pp. 63 - 67, 2012.

G. Shankar and K. Singh, "PID Parameters Tuning Using Modified Particle Swarm Optimisation and its Application in Load Frequency Control", 6th IEEE International Conference on Power Systems, New Delhi, India, pp. $1-6,2016$.

N. Y. Kouba, M. Menaa, M. Hasni, B. Boussahoua and M. Boudour, "Optimal Load Frequency Control Based on Hybrid Bacteria Foraging and Particle Swarm Optimisation", 11th International Multi Conference on Systems, Signals and Devices, Algiers, Algeria, pp. 776 - 785, 2014.

S. M. Razali, M. F. Rahmat and A. R. Husain, "Performance Comparison of Particle Swarm Optimisation and Gravitational Search Algorithm to the Design of Controller for Non-linear Systems" Journal of Applied Mathematics, Vol. 20, No. 14, pp. 1 - 9, 2014.

S. Duman, N. Yorukeren and I. H. Altas, "Load Frequency Control of a Single- Area Power System Using Gravitational Search Algorithm", International Symposium of Innovations in Intelligent Systems and Applications, Tradzon, Turkey, pp. 1-5, 2012.

H. M. Song, W. I Ibrahim and N. R. H. Abdullah, "Optimal Load Frequency Control in Single Area Power System using PID Controller based on Bacterial Foraging and Particle Swarm Optimisation”, ARPN Journal of Engineering and Applied Sciences, Vol. 10, No. 22, pp. 10733 - 10739, 2015.

S. Khajuria and J. Kaur, "Load Frequency Control of Interconnected Hydro- Thermal Power System using Fuzzy and Conventional PI Controller", International Journal of Advanced Research in Computer Engineering and Technology, Vol. 1, No. 8, pp. 65 - 72, 2012.

F. Liu, Y. Li, Y. Cao, J. She and M. Wu, "A Two-Layer Active Disturbance Rejection Controller Design for Load frequency Control of Interconnected Power System”, IEEE Transactions on Power Systems, Vol. 31, No. 4, pp. 3320 - 3321, 2016.

P. Prajapati and A. Parmar, "Multi-Area Load Frequency Control by Various Conventional Controller using Battery Energy Storage System", International Conference on Energy Efficient Technologies for Sustainability, Nargercoil, India, pp. 467 - 472, 2016.

S. K. Meena and S. Chanana, "Load Frequency Control of Multi-Area System Incorporating SMES Technology", International Conference on Energy, Power and Environment: Towards Sustainable Growth, Shillong, India, pp. $1-6,2015$.

H. Parvaneh, S.M. Dizgah, M. Sedighizadeh and S.T Ardeshir, "Load Frequency Control of Multi-Area Power System by Optimum Designing of Frequency Based PID controller using Seeker Optimisation Algorithm", 6th IEEE Conference on Thermal Power Plants, Tehran, Iran, pp. 52 - 57, 2016.

M.H Fini, G. R. Yousefi and H.H Alhelou, "Comparative Study on the Performance of Many-Objective and Single-Objective Optimisation Algorithms in Turning Load Frequency Controllers of Multi-area Power Systems", The Journal of Institutional of Engineering and Technology, Vol. 10, No. 12, pp. 2915 - 2923 , 2016.

R.N Rao and P.R.K Reddy, "PSO based Tuning of PID Controller for a Load Frequency Control in Two-Area Interconnected Power System", International Journal of Engineering, Research and Computer Applications, Vol. 1, No. 3, pp. 1499 - 1505, 2014.

S. Kansit and W. Assawinchaichote, "Optimisation of PID Controller Based PSOCoSA for an Automatic Voltage Regulation Systems”, International Electrical Engineering Congress, Chiang Mai, Thailand, pp. 87 92, 2016.

U.K Rout, R.K Salin and S. Pauda, "Gravitational Search Algorithm Based Automatic Generation Control for Interconnected Power System" International Conference on Circuits Power and Computing Technologies, Nagercoil, India, pp. 558 - 563, 2003.

A. Kumar and G. Shankar, "Priority Based Optimisation PID Controller for Automatic Voltage Regulator System Using Gravitational Search Algorithm", International Conference on Recent Developments in Control, Automation and Power Engineering, Noida, India, pp. 292 - 297, 2015.

J. O. Aibangbee, “Automatic Load Frequency Control of Two-Area Power System Using Proportional Integral Tuning Through Inter-Model Control”, IOSR Journal of Electrical and Electronics Engineering, Vol. 11, No. 2, pp. 13 - 17, 2016.

N. Y. Kouba, M. Menaa, M. Hasni, B. Boussahoua and M. Boudour, "Optimal Load Frequency Control based on Artificial Bee Colony Optimisation Applied to Single, Two and Multi-area Power Systems”, 3rd International Conference on Control Engineering and Information Technology, Tlemcen, Algeria, pp. 392 - 398, 2015.

M. Elsisi, M. Soliman, M. A. S. Aboelela and W. Mansour, "Dual Proportional Integral Controller of Two-Area Load Frequency Control based Gravitational Search Algorithm", Telkomnika Indonesian Journal of Electrical Engineering, Vol. 15, No. 1, pp. 26 - 35, 2015.

M.K Debnath, R.K Mallick, S. A. Aman, "Gravitational Search Algorithm Optimised Fuzzy-PID Controller Design for Load Frequency Control of an Interconnected Multi-Area Power System", International Conference on Circuit, Power and Computing Technologies, Nagercoil, India, pp. 1 - 6, 2015. 
S. Nag and N. Philip, "Application of Neural Network to Automatic Load Frequency Control", International Conference on Control, Instrumentation, Energy and Communication, Calcutta, India, pp. 15 - 50, 2014.

M. Kavya and G. S. Rao, "Tuning of PID Controller in an Interconnected Power System Using Particle Swarm Optimisation”, International Journal of Computer Applications, Vol. 118, No. 16, pp. 35 - 42, 2015.

T. K. Pati, J. R. Nayak, B. K. Sahu and B. Gantayat, "Load Frequency Control of an Interconnected Three-Area Thermal Power System using Conventional PID and Fuzzy-Logic Controller", International Conference on Energy, Power and Environment: Towards Sustainable Growth, Shillong, India, pp. 1 - 6, 2015.

R. Satheeshkumar and R. Shivakumar, "Ant Lion Optimisation Approach for Load Frequency Control of MultiArea Interconnected Power Systems", Circuits and Systems, Vol. 7, No. 9, pp. 2357 - 2383, 2016.

M. L. Klimontowicz, A. Al-Hinai and J. C. Peng, "Decentralised Sliding Mode Control for Load Frequency Problem in Three-Area Power Systems", Proceedings of the 8th IEEE Conference GCC and Exhibition, Muscat, Osman, pp. 1-5, 2015.

M. S. I. Aziz, S. W. Nawawi, S. Sudin, N. A. Waha, M. Faramarzi and M. A. Yusof, "Gravitational Search Algorithm Optimisation for PID Controller Tuning in Waste-Water Treatment Process", Jurnal Teknologi (Sciences and Engineering), Vol. 73, No. 3, pp. 103 - 109, 2015.

E. Rashedi, H. Nezamabadi-pour and Saryadzi, S. "A Gravitational Search Algorithm", International Journal of Information Science, Vol. 179, No. 13, pp. 2232 - 2248, 2009.

P. Kundur, Power System Stability and Control, McGraw-Hill, New York, 8th Edition, 2009.

V. R. A, "Generator and Transmission Line Characteristics Data", Volta River Authority, Akosombo, Ghana, $27 \mathrm{pp}, 2018$.

S. K. Mohapatra, M. Mohanty and N. K. Ray, "Application of GSA Optimised Controller Parameters in Automatic Generation Control for Interconnected Power System with Governor Dead Band", International Conference on Inventive, Systems and Control, Coimbatore, India, pp. 1 - 6, 2017.

S. Prakash and S. K. Sinha, "Neuro-Fuzzy Computational Technique to Control Load frequency in HydroThermal Interconnected Power System”, Journal of Institute of Engineers, Vol. 96, No. 3, pp. $273-282$, 2015.

S. Prakash, A. K. Bhardwaj and S. K. Sinha, "Neuro Fuzzy Hybrid Intelligent Approach for Four-Area Load Frequency Control of Interconnected Power System", 2nd International Conference on Power, Control and Embeded Systems, Allahabad, India, pp. 1-7, 2012.

Muthubalaji, S., Anand, R., \& Karuppiah, N. (2018). An integrated optimization approach to locate the DSTATCOM in power distribution system to reduce the power loss and total cost. Periodicals of Engineering and Natural Sciences, 6(2),

\section{APPENDIX}

\section{APPENDIX A}

\begin{tabular}{|c|l|c|c|}
\hline Parameter & Description & $\begin{array}{c}\text { Valu } \\
\text { e }\end{array}$ & Unit \\
\hline $\mathrm{R}_{1}, \mathrm{R}_{2}, \mathrm{R}_{3}, \mathrm{R}_{4}$ & Regulations of Governors in Areas 1,2,3,4 & 2.5 & $\mathrm{~Hz} / \mathrm{pu} \mathrm{MW}$ \\
\hline $\mathrm{K}_{\mathrm{T}}$ & Integral Controller Gains for Thermal Areas & 0.2 & $\begin{array}{c}\mathrm{Pu} \\
\mathrm{MW} / \mathrm{HzS}\end{array}$ \\
\hline $\mathrm{D}$ & Damping Coefficient & 0.01 & $\mathrm{PuMW} / \mathrm{Hz}$ \\
\hline $\mathrm{K}_{\mathrm{H}}$ & Integral Controller Gain in Hydro Area & 0.02 & $\mathrm{~S}$ \\
\hline $\mathrm{K}_{\mathrm{p} 1}, \mathrm{~K}_{\mathrm{p} 2}, \mathrm{~K}_{\mathrm{p} 3}$ & Power Systems Constants in Areas 1,2,3 \& 4 & 11 & $\mathrm{MW} / \mathrm{HzS}$ \\
\hline $\mathrm{K}_{\mathrm{p} 4}$ & & 100 & $\mathrm{~Hz} / \mathrm{puMW}$ \\
\hline $\mathrm{T}_{\mathrm{p} 1}, \mathrm{~T}_{\mathrm{p} 2}, \mathrm{~T}_{\mathrm{p} 33}$ & Power System Time Constants in Areas 1,2,3,4 & 16 & $\mathrm{Second}(\mathrm{S})$ \\
\hline $\mathrm{T}_{\mathrm{p} 4}$ & & & \\
\hline
\end{tabular}




\begin{tabular}{|c|c|c|c|}
\hline$\beta_{1}, \beta_{2}, \beta_{3}, \beta_{4}$ & Tie Line Bias Factor in Areas 1, 2, 3, 4 & $\begin{array}{l}0.41 \\
0\end{array}$ & $\mathrm{puMW} / \mathrm{Hz}$ \\
\hline $\begin{array}{l}\mathrm{T}_{\mathrm{o}}\left(\mathrm{T}_{12}, \mathrm{~T}_{13}\right. \\
\left.\mathrm{T}_{23}, \mathrm{~T}_{34}\right)\end{array}$ & $\begin{array}{l}\text { Synchronising Coefficients for Tie Line Four Area } \\
\text { Systems }\end{array}$ & $\begin{array}{l}0.08 \\
67\end{array}$ & MW/radian \\
\hline $\mathrm{T}_{\mathrm{g} 1}$ and $\mathrm{T}_{\mathrm{g} 2}$ & $\begin{array}{l}\text { Governor Time Constants for Thermal Areas } 1 \text { and } \\
2\end{array}$ & 0.08 & Second \\
\hline $\mathrm{T}_{\mathrm{t} 1}$ and $\mathrm{T}_{\mathrm{t} 2}$ & $\begin{array}{l}\text { Turbine Time Constants for Thermal Areas } 1 \text { and } \\
2 \text { S }\end{array}$ & 0.3 & Second \\
\hline $\mathrm{K}_{\mathrm{r} 1}$ and $\mathrm{K}_{\mathrm{r} 2}$ & $\begin{array}{l}\text { Reheat Turbine Constants (Gains) for Thermal } \\
\text { (Reheat) Areas } 1 \text { and } 2\end{array}$ & 0.5 & - \\
\hline Tw & Water Starting Time for Hydro Turbine & 1 & Second \\
\hline $\mathrm{T}$ & $\begin{array}{l}\text { Sampling Time in Discrete Equations of Power } \\
\text { Systems }\end{array}$ & 0.01 & Second \\
\hline $\begin{array}{r}a_{12}, \quad a_{13}, \quad a_{23}, \\
a_{34}\end{array}$ & $\begin{array}{l}\text { Ratio of Rated Powers of a Pair of Areas in the } \\
\text { Four Area System }\end{array}$ & 1 & \\
\hline $\mathrm{P}_{\mathrm{ri}}$ & Power of Each Area & 1000 & MW \\
\hline Ptie $_{\text {max }}$ & Tie-Line Power (Max) & 100 & MW \\
\hline $\mathrm{P}_{\text {nom }}$ & Nominal Operating Power & 500 & MW \\
\hline $\mathrm{F}$ & Nominal Frequency & 50 & $\mathrm{~Hz}$ \\
\hline $\mathrm{H}_{\mathrm{i}}$ & Per Unit Inertia Constant of $i^{\text {th }}$ Area & 4 & Seconds \\
\hline $\mathrm{k}_{\mathrm{p}}$ & Proportional Gain of Hydraulic Governor & 5.16 & - \\
\hline $\mathrm{k}_{\mathrm{i}}$ & Integral Gain of Hydraulic Governor & 5 & - \\
\hline $\mathrm{K}_{\mathrm{d}}$ & Derivative Gain of Hydraulic Governor & 4 & - \\
\hline
\end{tabular}

Table A1 Nominal parameters used in power system models 